\title{
Contribuições metodológicas para a análise dos sentidos em um estudo sobre atividade docente
}

Vanessa Cristina da Silval

Claudia Leme Ferreira Davis"

\section{Resumo}

0 presente artigo tem por objetivo realizar uma discussão a respeito do método utilizado em uma pesquisa que visa a identificar e explicar os sentidos e significados da atividade docente. A pesquisa é de caráter qualitativo e está fundamentada nos pressupostos teórico-metodológicos da psicologia sócio-histórica. Condizente com a linha teórica escolhida, opta ainda pela proposta metodológica de Aguiar e Ozella (2006), que sugerem a construção e a análise de "núcleos de significação". Dentre as categorias de análise oferecidas pelo referencial adotado, a fundamental para a pesquisa é a de sentido. A pergunta que move este estudo, frequentemente feita por muitos pesquisadores ou que, pelo menos, deve ser, é: como a escolha do método e dos procedimentos pode contribuir para a realização da análise? Sendo assim, a principal discussão que este artigo suscita - e, portanto, seu tema fundamental - é a contribuição de procedimentos já notórios, como a entrevista individual recorrente, e de procedimentos não tão usuais, como os recursos de sensibilização, nesse tipo de análise que busca a apreensão dos sentidos da atividade docente. 0 resultado da pesquisa evidencia que uma nova forma de entender e trabalhar com esses procedimentos pode possibilitar um maior domínio e envolvimento do pesquisador com o processo investigativo e, sobretudo, ampliar o alcance construtivo-interpretativo da análise. A conclusão assinala a necessidade de empregar novos instrumentos para análise dos sentidos.

\section{Palavras-chave}

Método - Sentido - Atividade docente - Entrevista individual Recursos artísticos.

I- Universidade Anhanguera de Taboão da Serra, Taboão da Serra, SP, Brasil. Contato: vanacris@yahoo.com.br II- Pontifícia Universidade Católica de São Paulo, São Paulo, SP, Brasil. Contato: claudiadavis@uol.com.br 


\title{
Methodological contributions for the analysis of meanings in a study on teaching
}

Vanessa Cristina da Silva'

Claudia Leme Ferreira Davis"

\begin{abstract}
This article aims to discuss the method used in a qualitative study intended to identify and explain the senses and meanings of teaching. It is based on the theoretical and methodological assumptions of historical social psychology and the methodological proposal of Aguiar and Ozella (2006), who suggest the construction and analysis of "nuclei of meanings". The categories of analysis provided by such framework include one that is fundamental for research: meaning. The question which drives this study and is or should be frequently asked by a number of researchers is: how may the choice of method and procedures contribute to analysis? Thus, the key subject of and the major discussion this article generates is the contribution of well-known procedures such as recurrent individual interviews and of procedures which are not so usual, such as awareness raising resources, in this kind of analysis that seeks to apprehend the meanings of teaching. The research has evidenced that a new way of understanding and dealing with these procedures fosters researchers' greater mastery of and involvement in the investigation process and may, above all, enhance the constructive-interpretative potential of the analysis. Finally, it indicates the need to employ new tools for the analysis of meanings.
\end{abstract}

\section{Keywords}

Method - Meaning - Teaching - Individual interview - Artistic resources.

I- Universidade Anhanguera de Taboão da Serra, Taboão da Serra, SP, Brasil.

Contact: vanacris@yahoo.com.br

II- Pontifícia Universidade Católica de

São Paulo, São Paulo, SP, Brasil.

Contact: claudiadavis@uol.com.br 


\section{Introdução}

Este artigo tem como objetivo apresentar e discutir questões relacionadas ao método utilizado para a produção de conhecimento sobre os aspectos subjetivos da atividade docente em uma pesquisa de mestrado em educação, especificamente em psicologia da educação, pela Pontifícia Universidade Católica de São Paulo (PUC-SP). A pesquisa, intitulada Um arte-educador no ensino não formal: um estudo dos sentidos e significados da atividade docente de arte e cultura em medida socioeducativa, está ancorada nos pressupostos teóricos da psicologia sócio-histórica, especialmente nas questões de método para Vigotsky (2004), e incorpora as contribuições teórico-metodológicas de Aguiar e Ozella (2006) quanto à construção e análise de "núcleos de significação".

Neste texto, enfatiza-se uma discussão sobre os procedimentos de produção de dados para a construção dos "núcleos de significação", a saber: a entrevista individual recorrente e a utilização de recursos de sensibilização, como instrumentos audiovisuais e de arte. É cada vez mais evidente que, para a apreensão dos sentidos, neste caso, os sentidos da atividade docente, a diversidade de instrumentos metodológicos apresenta-se como uma demanda, pois interpretar a palavra com significado em seus mais diferentes prismas, aspectos e conjunturas possibilita que o discurso seja dito a partir de múltiplos lugares e pontos de vista, qualidade que pode enriquecer todo o processo de análise. A experiência da alteridade permeada por recursos artísticos coloca o pensamento do sujeito em movimento, à medida que possibilita o exercício da imaginação. Faz-se importante esclarecer que os "núcleos de significação" constituem um método que contribui para o processo de análise dos sentidos. Dessa forma, a metodologia apresentada requer compreender o sujeito e, mais particularmente, a zona mais profunda e fluida de seus sentidos pessoais, e é utilizada em pesquisas acadêmicas para estudar diversos assuntos, mais comumente aqueles relacionados à educação, tais como: sentidos atribuídos pelos professores à formação inicial, sentidos produzidos pelo professor da educação infantil acerca da educação inclusiva, sentidos atribuídos à promoção da alimentação saudável na escola por professora do ensino fundamental, entre outros.

A relevância teórica da discussão proposta é justamente apresentar a contribuição da diversidade metodológica no movimento de coleta de dados e análise, uma vez que, na bibliografia existente, poucos são os trabalhos que abordam essa temática. De fato, a discussão que aqui se realiza pode revelar novos aspectos quanto à escolha e uso de instrumentos na atividade de pesquisa, permitindo, quiçá, o delineamento de novos parâmetros metodológicos para a produção de conhecimento sobre a atividade docente. No âmbito social, enfatiza-se a mudança de postura do pesquisador, que compreende a formação do ser humano e da sociedade em uma ação conjunta, contínua e intrínseca, ao evidenciar nuances do processo de construção de sentidos em um movimento que, por vezes, não é linear, mas sim contraditório, uma vez que o protagonista da história, o ser humano, constitui-se em sua relação com o mundo, em sua complexidade e historicidade.

\section{O método}

\section{Considerações iniciais: abordagem sócio-histórica e escolha do procedimento}

Ao buscar identificar e explicar os sentidos e significados que um arte-educador constitui para a atividade de arte e cultura que desenvolve junto a adolescentes cumprindo medida socioeducativa, entende-se ser fundamental especificar o percurso trilhado para focar o processo constitutivo dos sentidos. Destarte, é essencial ir além da aparência e alcançar uma visão mais aprofundada do fenômeno em estudo.

Parte-se, assim, do empírico, constituído por elucubrações descritivas do objeto/fenômeno, para caminhar em direção a sua superação. 
Para tanto, faz-se necessário um método que possa explicar e construir o fenômeno, em seu processo histórico (AGUIAR; OZELLA, 2006). De fato, a reflexão metodológica de Vigotsky (2004) para buscar novos meios de análise e de investigação em psicologia é impulsionada pelo que ele julgava ser o significado histórico da crise que essa ciência vivia. 0 autor supunha que essa crise tinha como manifestação externa a formação e a presença de diversas correntes e escolas, cada uma com propósitos distintos, que não se articulavam. Todavia, a origem da crise e sua maior problemática estavam profundamente ligadas à questão do método, ou seja, às categorias metodológicas e de análise, que não proporcionavam as condições necessárias para explicar o humano.

Nesse sentido, Vigotsky (2004) entendia que a falta de um método adequado deveria ser superada, de modo a se construir uma nova ciência psicológica, capaz de explicar desde as reações mais simples de estímulo/resposta até as mais elevadas produções da consciência. $\mathrm{Na}$ União Soviética da época, a nascente psicologia russa deveria partir da análise das diversas teorias e sistemas - o freudismo, o behaviorismo, o gestaltismo, a psicologia genética etc. - para criticar cada uma delas, segundo os princípios e conceitos derivados do materialismo histórico e dialético de Karl Marx.

Vigotsky (2004) defendeu a formulação de uma ciência psicológica geral, por meio de um método que conferisse unidade e conexão aos conceitos da psicologia e, ainda, especificasse seus objetivos, conferindo-lhe o status e o formato de uma ciência, e não de um aglomerado de fenômenos estudados mediante bases e/ou pressupostos falsos. 0 método de uma ciência concreta estrutura-se em suas bases filosóficas, mas só pode ser caracterizado pela natureza de seu objeto, sua construção e suas categorias de análise. 0 autor traz, no âmago de sua teoria, a junção da lógica e da história, como dois procedimentos inseparáveis na análise científica.

Para Vigotsky (2007), três princípios são fundamentais na construção de um método.
0 primeiro refere-se à importância de analisar os processos e não os resultados de um dado fenômeno. A tarefa básica da pesquisa é, assim, reconstruir como se deu o desenvolvimento daquilo que está em estudo, "fazendo com que o processo retorne aos estágios iniciais" (VIGOTSKY, 2004, p. 64). Esse princípio trata, notadamente, das transformações qualitativas pelas quais o fenômeno passa.

0 segundo princípio foca a explicação e não apenas sua descrição, distinguindo a aparência do fenômeno de sua essência. Não se descarta, certamente, o momento da descrição, pois há que descrever o empírico para organizá-lo. 0 central é ter em mente que a simples descrição não permite alcançar a gênese do fenômeno e suas relações dinâmicas e causais. É preciso, portanto, superar a descrição de sua aparência, para alcançar sua essência, isto é, as múltiplas determinações que a constituem. Como afirma Vigotsky (2007, p. 66), “o tipo de análise objetiva que defendemos procura mostrar a essência dos fenômenos psicológicos em vez de suas características perceptíveis".

E, por fim, o terceiro princípio refere-se ao problema do "comportamento fossilizado”, já que, ao longo da história, alguns comportamentos vão se tornando mecânicos e automatizados, razão pela qual acabam sendo também naturalizados. Nesse processo, os comportamentos acabam por perder sua aparência original, de modo que de nada adianta centrar a atenção em sua aparência externa: ela nada revela sobre sua essência. É como se, ao longo de seu desenvolvimento histórico, esses comportamentos tivessem esmorecido e, na repetição contínua, sedimentado-se, tornando-se fossilizados.

Não obstante, esses comportamentos constituem uma forma superior de comportamento humano, que pode ser facilmente confundida com uma forma inferior, difıcultando sua análise. É necessário, então, ter clareza acerca das mudanças e dos processos pelos quais o comportamento passa, uma vez que "o pesquisador é frequentemente forçado 
a alterar o caráter automático, mecanizado e fossilizado das formas superiores de comportamento, fazendo-as retornar a sua origem" (VIGOTSKY, 2007, p. 68). Com esse embasamento, o procedimento adotado para a análise dos dados foi o proposto por Aguiar e Ozella (2006), tendo por objetivo identificar e explicar os sentidos e significados que um arte-educador constitui para a atividade de arte e cultura que desenvolve junto a adolescentes cumprindo medida socioeducativa.

Conforme indicam Bogdan e Biklen (apud TRIVIÑOS, 1992) e Ludke e André (1986), na pesquisa qualitativa, a interpretação é o foco e o pesquisador é a chave do processo interpretativo, cabendo-lhe evidenciar qual é o significado do fenômeno para aqueles que o vivem. Ao iniciar a formulação de um projeto acadêmico, é relevante uma visão de pesquisa coerente com os pressupostos teóricos e metodológicos adotados. Dito isso, a interpretação não consiste em tratar o qualitativo como oposto ao quantitativo. $\mathrm{Na}$ perspectiva histórica e dialética, as abordagens quantitativa e qualitativa são parte de um mesmo todo; certamente distintas, são também complementares, na medida em que uma constitui a outra sem, contudo, se fundirem. $\mathrm{Na}$ perspectiva materialista, histórica e dialética, o "método deve levar em conta o processo histórico de constituição do sujeito na relação com a realidade, inclusive as possibilidades de mudança nele gestadas por meio da pesquisa" (SOARES; BARBOSA, 2010, p. 45).

\section{0 sujeito da pesquisa}

Para a escolha do sujeito, alguns critérios foram estabelecidos:

a) trabalhar como arte-educador em medida socioeducativa em um dos quatro convênios estabelecidos entre a Fundação CASA e as organizações não governamentais (ONGs) - Cenpec de São Paulo, Ação Educativa de São Paulo, Grupo de Amparo aos Doentes da AIDS (GADA) do interior de São Paulo, e Centro de Educação e Assessoria Popular (Cedap) do litoral de São Paulo - ou em ONGs parceiras na gestão da medida socioeducativa;

b) contar com ampla e heterogênea experiência no ensino de arte e cultura para alunos em medida socioeducativa, situação que permitiria ao arte-educador alcançar uma visão mais ampla de sua função;

c) ter expressado, durante os encontros de formação observados pela pesquisadora, falas adequadas e pertinentes para se cumprir o objetivo da pesquisa.

Com base nesses critérios, optou-se por trabalhar com um arte-educador que mantivesse vínculo com uma organização conveniada à Fundação CASA (critério a), dispondo de mais de dois anos de experiência (critério b), em pelo menos três centros educacionais (critério c). $\mathrm{Na}$ condição de técnica na área de arte e cultura, a pesquisadora pôde estabelecer contato mais próximo com os educadores dessa instituição, durante reuniões em que se discutiam o objetivo do trabalho e o desenvolvimento das atividades.

A fala desses profissionais quanto à atuação em medida socioeducativa e o enfoque criativo das atividades com intencionalidade educativa foram tão impactantes que levaram a pesquisadora a frequentar outras ações culturais que realizavam. A partir dos critérios mencionados, dois sujeitos destacaram-se para a pesquisa, e, por razões de conveniência da pesquisadora, apenas um deles foi selecionado. Neste trabalho, para efeitos de sigilo, foi-lhe dado um nome fictício. A pesquisadora entrou em contato com o arte-educador para convidá-lo a participar do estudo e ele anuiu prontamente.

0 sujeito do estudo, aqui batizado Lucas, 37 anos, nasceu em Anápolis, Goiás, é casado e pai de dois filhos. Ainda na infância, por volta de nove anos, trabalhava catando lixo em um aterro sanitário, juntamente com dois irmãos. Interrompeu os estudos no $2^{\circ}$ ano do ensino médio, mas pretende voltar a estudar. Veio para São Paulo aos dezessete anos e, em meio a sua vivência atribulada de conflitos, teve um encontro decisivo com a 
arte e começou a integrar um grupo de dança de rua. Há quinze anos, por meio do convite de um amigo que desenvolvia um projeto social ligado ao esporte, mais especificamente ao skate, iniciou sua carreira de arte-educador, ministrando dança de rua no S.O. S. Criança, instituição responsável por abrigar crianças e adolescentes em situação de rua e autores de atos infracionais. Não possui formação pedagógica, mas dentro em breve pretende cursar uma faculdade para discursar melhor sobre o conhecimento técnico. É presidente da associação de moradores de sua comunidade, localizada na periferia de São Paulo, comunidade essa que compreende de 3.000 a 3.500 pessoas. Há quatro anos, ocasião em que a ONG iniciou o projeto artístico e cultural em medida socioeducativa, Lucas foi contratado e atualmente é um dos arte-educadores mais antigos e experientes do projeto.

A opção por um único sujeito não afeta o poder de generalização da pesquisa e é possível no quadro teórico e metodológico adotado. A generalização, na abordagem sócio-histórica, não permite estender seus resultados nem comparar fenômenos com base em sua aparente similitude. Ao contrário, a generalização, nessa modalidade de pesquisa, refere-se à capacidade explicativa do fenômeno, a ser buscada em seu desenrolar e em suas mediações constitutivas, ou seja, as relações estabelecidas e sustentadas pela teoria para entender o fenômeno podem proporcionar a expansão do conhecimento alcançado para além do sujeito particular estudado e, portanto, explicar uma parcela concreta da realidade própria de um dado contexto.

\section{Procedimentos}

Os procedimentos empregados neste trabalho para a obtenção das informações necessárias foram: a) entrevista individual recorrente, com o propósito de retomar as falas do sujeito tantas vezes quanto se julgasse necessário para alcançar uma melhor compreensão sobre o narrado; b) apresentação de dois vídeos, que mantinham clara relação com o universo do entrevistado - Se ela dança, eu danço e Lixo extraordinário -, ambos utilizados como recurso de sensibilização, ou seja, como meio de reavivar lembranças e sentimentos relacionados à história de vida do sujeito, na medida em que se acredita que as relações e situações vividas engendram a constituição dos sentidos e signifıcados da atividade em geral e do docente em particular ${ }^{1}$; c) apresentação de variadas obras de arte de Candido Portinari, Alfredo Volpi, Caribé, Di Cavalcanti, Glênio Biancheci, Osvaldo Goeldi etc., que foram colocadas diante do sujeito para permitir que ele expressasse, por meio delas, o sentido da atividade artística e cultural que desenvolvia junto a adolescentes cumprindo medida socioeducativa. Partiu-se do pressuposto de que esse conjunto de obras artísticas mobilizaria emoções no sujeito e facilitaria o contato e a comunicação, como bem aponta Altenfelder (2006, p. 44):

\begin{abstract}
A escolha de uma obra de arte foi utilizada como instrumento de coleta, pois, no nosso entender, a arte é uma linguagem que facilita a comunicação e a expressão dos sentimentos e emoções, permitindo que sentidos sejam expressos com maior facilidade, e proporcionando indícios que podem auxiliar o pesquisador a desvelar a realidade a ser estudada.
\end{abstract}

0 procedimento empregado nos dois últimos parágrafos para aprofundar a investigação dos sentidos e significados da atividade artístico-cultural do participante junto aos jovens pode ser considerado como:

[...] recurso, todavia, é assumido, em geral, como instrumento projetivo, capaz de suscitar e de projetar, para fora do individuo, os elementos mais intrínsecos

1- 0 primeiro vídeo mostrou a apresentação de dança de um jovem tentando vencer um concurso e o segundo apresentou trechos do documentário do artista plástico Vik Muniz, cujo trabalho transformou material reciclável em arte, e também a vida daqueles que trabalhavam e viviam em um lixão. 
da estrutura da estrutura e funcionamento da psique, mais precisamente dos aspectos emotivos, considerados em singularidade a partir de dados quase sempre apenas bibliográficos. (BARROCO, 2007, p. 21).

Para fins de análise, tanto os relatos feitos durante a entrevista recorrente como os comentários do participante sobre as obras de arte e sua profıssão foram gravados e posteriormente transcritos.

0 procedimento ético também compõe um aspecto imprescindível à produção de uma pesquisa. Assim, inicialmente, o entrevistado teve a oportunidade de ler e preencher o Termo de consentimento livre e esclarecido, o qual permitiu ao sujeito compreender o significado, o alcance e os limites de sua participação na pesquisa, assim como também a justificativa, objetivos, procedimentos e metodologia utilizada. Tal documento visa a esclarecer que a participação no estudo é completamente voluntária e que pode ser interrompida a qualquer momento, sem nenhuma penalidade. Durante o trabalho, o entrevistado não correu riscos ou desconfortos, uma vez que, para garantir sua privacidade, nem seu nome, nem o da instituição na qual trabalha foram revelados. Vale salientar, no entanto, que os resultados da pesquisa podem ser divulgados em publicações científicas, desde que os dados pessoais do sujeito não sejam mencionados. 0 Termo de consentimento livre e esclarecido foi encaminhado ao Comitê de Ética em Pesquisa (CEP) da Pontifícia Universidade Católica de São Paulo (PUC-SP), juntamente com um ofício de apresentação do projeto e o termo de compromisso dos pesquisadores responsáveis.

Em face da análise dos documentos mencionados, o referido Comitê aprovou a realização da pesquisa.

\section{Encontros}

Foram realizados quatro encontros. No primeiro, foram apresentados ao sujeito o projeto e o objetivo da pesquisa, bem como os instrumentos que seriam utilizados na produção e na coleta dos dados de interesse. Nesse contato preliminar, agendaram-se ainda os dias e os horários mais adequados para os próximos, de acordo com a disponibilidade do participante. No segundo encontro, foi feita a entrevista, seguindo um roteiro semiestruturado, com perguntas abertas e fechadas.

Aguiar (2006) salienta que a entrevista é um instrumento adequado para pesquisas que buscam apreender os processos psíquicos, principalmente os que envolvem os sentidos e significados que sujeitos constituem sobre um determinado fenômeno. Esse tipo de entrevista permitiu um diálogo bastante informal do participante com a pesquisadora, que se sentiu livre para retomar alguns assuntos, solicitando maiores explicações, algo que conferiu flexibilidade ao processo (LUKE; ANDRÉ, 1986).

A questão norteadora da conversa foi a própria história de vida do participante: sua família, naturalidade, formação profissional, início de carreira, motivos da escolha profissional, concepção de educação, atuação em medida socioeducativa, qual a relação entre arte e cultura com educação, conquistas, obstáculos, como é ser educador, entre outros questionamentos.

0 terceiro encontro foi iniciado com uma retomada da conversa mantida no encontro anterior para, depois, apresentar os dois vídeos, na tentativa de desencadear a reflexão sobre sua atuação docente a partir de lembranças de sua vida e atividade profissional e, em seguida, empregar as obras de arte como recursos de aprofundamento da investigação dos sentidos e significados da atividade artístico-cultural do participante junto aos jovens. Finalmente, o quarto e último encontro buscou oferecer ao entrevistado uma devolutiva, para que ele tomasse ciência dos resultados obtidos por meio de suas falas e, ainda, das conclusões alcançadas neste trabalho. Com o consentimento do participante, o trabalho final foi, em momento oportuno, discutido com os coordenadores do projeto Arte na Casa ${ }^{2}$ e seus educadores.

2- A fim de firmar uma parceria com a Fundação Casa, a ONG elaborou um projeto, que prevê a realização de oficinas artísticas e culturais para adolescentes do programa de internação. As oficinas abarcavam quatro grandes áreas: artes do corpo, artes da palavra, artes visuais, artes cênicas. Cada uma delas subdividia-se em modalidades específicas, como, respectivamente, street dance, literatura, cinema e vídeo, teatro, entre outras. 
Apresentar o resultado da pesquisa para o entrevistado deve ser um compromisso ético do entrevistador para com o sujeito de sua pesquisa. É nesse momento que a pesquisa alcança um novo patamar, pois aufere o poder de transformar o sujeito e, por conseguinte, sua prática educativa. 0 sujeito pode ouvir seu discurso por meio de uma retomada proposta pelo entrevistador, o que gera um momento propício para a reflexão. Ao ouvir sua fala e perceber as contradições que permeiam sua concepção de si, do aluno e do mundo, o participante pode reavaliar suas ideias e práticas, o que, assim, permite um momento singular e egrégio, o surgimento, ou melhor, a constituição do novo.

\section{- destaque para a entrevista e os recursos de sensibilização:}

uma fértil discussão

Convém, nesse momento do texto em que os pressupostos teórico-metodológicos e os procedimentos foram devidamente apresentados, aprofundar o processo da entrevista individual recorrente e dos recursos artísticos.

A entrevista individual recorrente é o procedimento mais indicado e, portanto, o mais usual para obter as informações necessárias para a apreensão dos sentidos compreendidos no processo de construção dos “núcleos de significação". Nessa modalidade de entrevista, após uma primeira leitura, o entrevistado deve ser informado, a fim de eliminar dúvidas, aprofundar contradições, e permitir uma análise quase conjunta do processo. É notório que a entrevista possibilita o acesso aos processos psíquicos fundamentais que nos aproximam das zonas de sentido, mas, sobretudo, deve-se frisar que esse é o momento no qual o sujeito da pesquisa se desnuda aos olhos do entrevistador, que deve ser astuto o suficiente para perceber quem é aparentemente esse sujeito, seus motivos e conflitos sobre a atividade que desempenha. Como já foi dito, a aparência, por vezes, não diz nada sobre a essência, mas é o ponto de partida para a apreensão dos sentidos.
Não pode haver pressa nesse momento que caracteriza a construção do vínculo, da confiança entre entrevistador e entrevistado. 0 sujeito deve sentir-se à vontade para compartilhar com o entrevistador experiências e lembranças por vezes dolorosas de seu passado e presente. Uma memória que vem à tona a partir de uma indagação do entrevistador pode parecer não ter clara relação com a pergunta, mas o olhar analítico, que é imperativo ao entrevistador, não pode deixar de estabelecer a fecunda relação de uma vivência aparentemente isolada com a situação real e social do sujeito.

Desse modo, a entrevista possibilita a construção da confiança, da escuta atenciosa e substancialmente analítica e, principalmente, permite que o entrevistador inicie o processo de conhecer o sujeito do estudo em profundidade. Muitas vezes, os procedimentos adotados em uma pesquisa já estão estabelecidos antes mesmo de se conhecer o sujeito. Assim, uma contribuição relevante da entrevista inicial está em, sobretudo, oferecer bases coerentes e consistentes para se delinear novamente os procedimentos utilizados de posse do conhecimento das características principais do sujeito.

No estudo em questão, o projeto inicial incluía apenas a apresentação das variadas obras de arte. Contudo, ao reconhecer o sujeito, o padrão estabelecido foi reavaliado. 0 resultado foi a introdução de um novo procedimento, em conformidade com os objetivos já estabelecidos, para a utilização de recursos de sensibilização e mobilização. A questão central desse novo instrumento - os vídeos Se ela dança, eu danço e Lixo extraordinário - esteve justamente em se tratar de elementos que fazem parte do mundo do sujeito no presente ou passado. Ficou evidente, até mesmo para o entrevistado, que a pesquisadora ouviu a história que lhe foi contada e se mostrou capaz de e interessada em trabalhar de forma especifica os seus fatos. 0 sujeito se reconheceu em cada história e homem apresentado no filme. Seu envolvimento foi intenso: emocionou-se, alegrouse, indignou-se, identificou-se, enfim, viveu e reviveu suas vicissitudes em um constante 
movimento contraditório e complementar de olhar a si e agir no mundo.

Quanto à apresentação do repertório artístico, que compreendeu variadas obras de arte, Lucas teve de escolher uma obra para, por meio dela, expressar os sentidos de sua atividade. Após observar atentamente todas as obras, o sujeito optou pela xilogravura intitulada Os pescadores, de Oswaldo Goeldi. Claramente, a pintura em preto e branco e o título são aspectos que mobilizam a reflexão do sujeito na tentativa de expressar os sentidos daquilo que faz. Os dois elementos pareceram permitir-lhe um olhar mais concentrado e focado em si mesmo. De fato,

[...] os afetos, as emoções e os sentimentos são revelados nos desenhos, pelo uso das cores: a quantidade de colorido, seja referente ao número de cores diferentes utilizadas, seja quanto à área ou o escopo do colorido; o uso de tons claros ou escuros; o transbordamento da cor sobre o contorno do desenho; a escolha de determinadas cores; o riscar em traços fortes; o misturar cores para a produção de nuances. A cor tem sido considerada em oposição à forma, quanto ao significado básico: enquanto expressaria a vida emocional e afetiva, a forma representaria as atividades intelectuais. (VAN KOLCK, 1984, p. 51-52).

$\mathrm{Na}$ obra escolhida por Lucas, o preto predomina, de modo que apenas o contorno do corpo das pessoas retratadas é visto. Suas silhuetas, marcadas somente por uma tênue linha branca, separam-nas do fundo preto da tela. 0 preto, por sua vez, parece "indicar vida interior sombria, depressão, conflitos não solucionados, tristeza, inibição e repressão" (VAN KOLCK, 1984, p. 52). Para Lucas, a atividade do pescador e sua própria possuem estreita relação, motivo pelo qual a gravura foi escolhida, como revela a sua própria fala:

Porque os caras são pescadores. Esse é o... é... Às vezes, a relação que eu faço com meu trabalho é assim é... nós vamos é... às vezes, a gente... Eu vou pescar e eu sinto que [no trabalho] que tô indo para uma pescaria, entendeu? Mas o título mesmo de pescador vem muito ao encontro, porque eu faço esse papel de pescador, eu encontro pessoas...

As falas acima sugerem que, para Lucas, sua atividade é semelhante à do pescador, pois, se este almeja encontrar, buscar o peixe, o educador pretende encontrar pessoas, um dos vários sentidos que constituiu para sua atividade. 0 peixe representa, para o pescador, alimento, o sustento de sua vida. E as pessoas, são como joias raras, diamantes brutos, fonte de inspiração para Lucas.

A contribuição do uso desse tipo de repertório artístico está em compreender que o sujeito não escolhe somente a pintura anunciada na obra, mas todo o seu contexto de cores, título, tempo e espaço. Ele imagina quem são aqueles seres desenhados, o que fazem e como fazem e, a partir de então, expressa-se de forma fluida e criativa ao tecer elucubrações sobre o sentido de sua atividade.

Tanto os vídeos quanto as obras de arte funcionaram como catalizadores de emoções, pensamentos e palavras do sujeito. Diante dos vídeos, Lucas, pareceu estar frente a frente com circunstâncias já vistas e vividas, fato que auxiliou sua expressão e comunicação. 0 sujeito teve como pano de fundo a história de outro ser e, na presença desse recurso, fez juízos de valor, criticou e desenvolveu uma linha de pensamento que muito revela sobre seu modo de sentir, pensar e agir no mundo. E, perante as obras de arte, ele fez sua escolha sem pressa. Olhou atentamente obra por obra, até que, em um determinado momento, parou e observou todos os detalhes daquela gravura. Nesse momento, o olhar e pensamento do sujeito foram postos em movimento, pois concentrou a análise das figuras na pintura e ao mesmo tempo se expandiu ao encontrar, na figura, elementos para expressar os sentidos subjetivos de sua atividade. 


\section{Análise}

É fundamental afirmar, neste momento, que entendemos a palavra com significado como a primeira unidade a destacar-se nessa fase ainda empírica da pesquisa. Conforme orientam Aguiar e Ozella (2006), as falas do sujeito, tanto na entrevista quanto no relato da escolha de uma dada obra de arte capaz de expressar e traduzir a atividade que realizava, foram transcritas e lidas inúmeras vezes. Em seguida, foi feita uma primeira organização dos temas tratados, considerando sua frequência e carga emocional.

Obteve-se, assim, um primeiro agrupamento, denominado pré-indicador formado simplesmente pelas falas, frases, expressões ipsis litteris do entrevistado. Identificados esses temas - os pré-indicadores, eles foram aglutinados por similaridade, proximidade, complementaridade e contradição, originando o que se denominou indicadores. Finalmente, a releitura do material e dos indicadores aglutinados permitiu a articulação dos indicadores, que formaram e geraram os núcleos de significação, por meio dos quais se procurou desvendar os sentidos e significados que um arte-educador constitui para a atividade de arte e cultura desenvolvida junto a adolescentes cumprindo medida socioeducativa. Convém esclarecer que cada grupo de préindicadores, aglutinados segundo os critérios acima citados, foi nomeado pelo pesquisador por um título que expressa a principal temática daquele grupo de pré-indicadores. De tal modo, o indicador é justamente o título construído pelo pesquisador para aquele grupo de pré-indicadores. Esse movimento construtivo-interpretativo perfaz todo o processo desde o inicio e é extremamente importante, já que o pesquisador, ao interpretar e construir o nome do indicador e núcleos de significação, deve se ater à essência do fenômeno abordado nesse grupo, isto é, o título/nome dado ao indicador e núcleos deve expressar o cerne da questão. Do contrário, as análises nada exprimem do sujeito e de sua atividade e, por conseguinte, não cumprem o objetivo da pesquisa. Por exemplo, um grupo de falas destacadas por sua frequência e carga emocional foi aglutinado por sua similaridade ou contradição, como: "Não tem como você dançar sem fazer matemática porque você precisa contar os tempos"; "Música com matemática estão revolucionando, uns caras fantásticos"; "Então, formas como essas caminham bem, você trabalha na dança gravidade, que é física!”; “A gente acaba falando pouco da dança porque tem um objetivo maior que a própria dança, entre outros". Esse conjunto de falas do próprio entrevistado, por meio da interpretação do pesquisador, recebe um título, ou seja, foi nomeada por indicador Articulação educação e cultura: revolução. Esse indicador é agrupado com um ou mais indicadores, como Atividade transformadora - Eles encontram de tudo no mar: as necessidades deles. Assim, os indicadores, ao ser agrupados, constroem a sua máxima expressão, o núcleo de significação Sentidos e significados da atividade de arte e cultura em medida socioeducativa: revolucionar para transformar.

Cada núcleo foi analisado, em um primeiro momento, procurando-se compreender melhor os assuntos nele tratados, uma análise aqui denominada intranúcleo. Destarte, a pesquisadora percorreu a fala do sujeito com o propósito de desvelar aquilo que era nele único e singular: sua história de vida. Ademais, pode-se afirmar que, ao investigar a trajetória de um representante dessa categoria de profissionais, é possível também agregar algum conhecimento sobre o coletivo profissional ao qual pertence, pois a construção dos sentidos subjetivos mantém uma relação dialética com o social.

Os cinco núcleos de significação tecidos neste estudo trouxeram aspectos importantes para a apreensão dos sentidos que aparentemente Lucas constitui da sua atividade profissional. No esforço construtivo-interpretativo, as inferências feitas nos núcleos de significação tiveram o propósito de alcançar sínteses cada vez mais organizadas e, assim, 
permitir uma maior aproximação das zonas de sentido do sujeito.

Por fim, foi realizada uma análise internúcleos, tentando construir a trama interpretativa que liga todos os núcleos entre si, desvendando os aspectos centrais do sujeito e, além disso, expandindo, por meio de teorizações, o conhecimento alcançado para o campo da educação. 0 movimento analítico tenta, portanto, organizar o caráter caótico do empírico, o concreto-dado, para, via sucessivas abstrações, alcançar outro, organizado, o concreto-pensado:

Isto quer dizer que o objetivo da pesquisa é explicar o concreto, ou seja, a realidade. Para isto é preciso transpor, pela faculdade de abstração, o concreto dado para nossa mente, produzindo assim o concretopensado, que é na realidade o concreto dado transposto para mente humana. Após, feita esta transposição, deve se voltar novamente o concreto pensado para o concreto dado, pois os dois devem estar em íntima relação. Afınal, se fosse de outra forma, a pesquisa não teria sentido, na medida em que não conseguiria explicar a realidade, fim último de qualquer pesquisa realmente compromissada e livre. (SANTOS, 2004, p. 8).

Segundo Altenfelder (2006), é possível voltar novamente ao empírico, certificando-se de que um maior entendimento do fenômeno é alcançado. A função do pesquisador não é, portanto, apenas a de coletar dados e/ou produzir informações, mas sim a de construí-los com base na relação que os dados mantêm com o entrevistado e com a realidade. A tentativa é alcançar um novo saber, pois "o conhecimento produz-se em um processo construtivo-interpretativo do pesquisador sobre as expressões múltiplas e complexas do ser estudado" (GONZÁLEZ REY, 2005, p. 47).

A análise internúcleo não é uma repetição ou resumo dos aspectos já tratados nas análises anteriores. 0 seu princípio está precisamente em identificar e apresentar analiticamente a relação de aspectos que estão presentes em todos os núcleos de maneira direta ou indireta, enfatizando assim a unicidade da análise. Por exemplo, para entender os sentidos subjetivos da atividade de Lucas, mote do quinto núcleo, foi fundamental compreender sua concepção de educação, de homem, de mundo, de teoria e prática, assuntos tratados em outros núcleos, mas que estão presentes de forma indireta nos sentidos de sua atividade. A análise internúcleos deve trazer algo novo ao revelar, por meio da articulação dos núcleos, a relação imbricada em seus mais diversos elementos.

A análise é um momento extremamente basilar para a pesquisa, pois confere a sua legitimidade e excelência ao atestar se os objetivos foram ou não alcançados. A construção analítica é uma tarefa complexa que exige do pesquisador tanto inspiração quanto transpiração. Ele deve retomar os elementos fundamentais da pesquisa, como tema, problema, objetivo, relevância e referencial teórico, a fim de transcrever uma análise coerente. E é nesse momento da construção da análise que a escolha do método e dos procedimentos empregados é posta em xeque.

A escolha do referencial teórico traz tanto possibilidade quanto limites à pergunta do pesquisador e oferece consistência e coesão ao trabalho apresentado. Demo (2009, p. 31) argumenta que "o referencial teórico representa o fiel da balança da pesquisa, porque é nele que se encontram soluções para a maioria das dúvidas, tais como: que dados interessam, que dados produzir, o que ler" e que "quando o pesquisador se sente perdido ou não encontra apoio para decidir se já fez o suficiente ou não, significa que seu referencial teórico não está à altura ou sumiu de vista." Ter claros os princípios e alcance do referencial teórico e metodológico escolhido orienta o olhar do pesquisador e, assim, subsidia a forma de se estudar o fenômeno.

$\mathrm{Na}$ pesquisa em questão, o uso da entrevista individual recorrente e, principalmente, dos recursos de sensibilização 
é decisivo no momento da análise, pois eles inquietam e instigam o pesquisador ao lhe oferecer elementos e informações que ainda não estão prontos ou acabados, mas que necessitam de sua leitura para ser compreendidos no todo. 0 sujeito frente à obra de arte é levado a expressar especialmente os sentidos de sua atividade, não obstante, nesse movimento, também aparecem seus desejos, pensamentos, impressões, atitudes e medos, elementos que muito exprimem sobre ele e que, portanto, são necessários para a construção de uma análise consistente e rica. Tal análise ganha um colorido vibrante através do olhar interpretativo do pesquisador. Assim, os procedimentos citados, a partir de uma nova forma de compreensão e utilização por parte do pesquisador, podem conferir uma análise de grande alcance, capaz de apreender mais precisamente o sujeito, seus sentidos e motivos de seus pensamentos e atividades ao revelar a unidade ação, pensamento e afeto.

\section{Conclusão}

Para compreender o humano em sua contradição e historicidade, a produção de conhecimento lida com um material complexo: a vida humana e o seu sujeito. Assim, para identificar e explicar os sentidos da atividade docente, é necessário conhecer o homem em sua relação com o mundo social, uma vez que homem e mundo se constituem mutuamente em um movimento dialético. 0 homem, ao transformar a natureza, ou seja, seu universo social, transforma ao mesmo tempo a si próprio. A partir dessa concepção teórica de homem e mundo presente na psicologia sócio-histórica, a escolha do método é um passo importante, pois este deve estar condizente com os pressupostos teóricos. A construção e análise dos "núcleos de significação" é um método que surge para auxiliar o pesquisador no desafıo de analisar o processo em sua gênese, privilegiando a explicação em sua essência e não apenas aparência e, principalmente, orientando uma análise que compreende o comportamento do homem em sua origem social.
Posto tal desafio, é preciso inovar nos procedimentos utilizados para coleta de dados, a fim de operar um salto qualitativo nesse percurso. Sendo assim, aprimorar os objetivos e propósitos da entrevista inicial recorrente é um aspecto interessante a ser discutido e adotado. Ouvir o sujeito e sua história de vida proporciona pistas para tecer considerações sobre quem se acredita ser o sujeito, os motivos e sentidos de sua atividade. E mais, conhecer o sujeito pode ser decisivo para que o pesquisador sinta a necessidade de trazer, em um segundo encontro, como recurso de sensibilização, um material escolhido especialmente para o entrevistado, por apresentar uma clara relação com o universo do sujeito. $\mathrm{Na}$ pesquisa em questão, esse tipo de material é caracterizado pelo termo sob medida.

Para os pesquisadores iniciantes, acredita-se que esse movimento é muito rico, pois pode elevar o nível de envolvimento do pesquisador com o processo investigativo e o alcance interpretativo da análise, extrapolando os horizontes do empírico. Por meio de recursos artísticos e audiovisuais, é oferecida ao sujeito a oportunidade de sonhar, imaginar, inventar, fazer analogias, e ao pesquisador, a possibilidade de construir novas hipóteses, histórias, interpretações, olhares. E, para ambos, o processo é permeado pela conquistada de novas práticas, de uma nova ação no mundo.

Ao afırmar que o ponto de partida para a apreensão dos sentidos é a palavra com significado, diversificar os procedimentos envolvidos nessa ação-situação em que a palavra é dita é imperativo.

Assim, com base nas conjecturas perfiladas, a escolha do método e dos procedimentos pode contribuir para a realização da análise, à medida que eles orientam o pesquisador na apropriação de um suporte teórico necessário para a edificação de uma concepção de homem e mundo e para a construção de uma análise rica de aspectos interpretativos, gestados pelo contato tanto do sujeito quanto do pesquisador com recursos de sensibilização que atingem o sujeito em maior 
profundidade e completude, ou seja, em sua cognição, afetos e atividades.

Desse modo, o artigo presente não pretende esgotar o assunto ou limitar as inovações dos procedimentos metodológicos a recursos artísticos, e sim enfatizar sua grande contribuição, ao elevar o nível da leitura interpretativa que confere corpo à análise e, ainda, ir além, abrindo novos horizontes para pesquisas que abordem e utilizem novos meios tanto para explicar o homem quanto para aproximar-se das zonas de sentidos da atividade docente.

\section{Referências}

AGUIAR, Wanda Maria Junqueira (Org.). Sentidos e significados do professor na perspectiva sócio-histórica: relatos de pesquisa. 1. ed. São Paulo: Casa do Psicólogo, 2006.

AGUIAR, Wanda Maria Junqueira; OZELLA, Sérgio. Núcleos de significação como instrumento para a apreensão da constituição dos sentidos. Psicologia Ciência e Profissionalização, Brasília, v. 26, n. 2, jun. 2006. Disponível em: <http://pepsic.bvsalud.org/scielo.php?script=sci_arttext \&pid=S141498932006000200006\&lng=pt\&nrm=iso>. Acesso em: 18 set. 2010.

ALTENFELDER, Anna Helena. Formação continuada: os sentidos atribuídos na voz do professor. In: AGUIAR, Wanda Maria Junqueira (Org.). Sentidos e significados do professor na perspectiva sócio-histórica: relatos de pesquisa.1.ed. São Paulo: Casa do Psicólogo, 2006.

BARROCO, Sonia Mari Shima. Psicologia educacional e arte: uma leitura histórico-cultural da figura humana. Maringá: Edum, 2007.

DEMO, Pedro. Pesquisa e construção do conhecimento: metodologia científica no caminho de Habermas. Rio de Janeiro: Tempo Brasileiro. 2009.

GONZÁLEZ REY, Fernando. Pesquisa qualitativa e subjetividade: os processos de construção de informação. São Paulo: Pioneira Thomson Learning, 2005.

LIXO EXTRAORDINÁRIO - Trailler Oficial. Direção de Lucy Walker. Codireção de João Jardim e Karen Harley. Produção de Angus Aynsley e Hank Levine. [São Paulo]: Downtown, 2010. Disponível em: <https://www.youtube.com/watch?v=_pyR9qCd2F8>. Acesso em: jun. 2011.

LUDKE, Menga; ANDRÉ, Marli Elisa Dalmazo. Pesquisa em educação: abordagens qualitativas. São Paulo: EPU, 1986.

SANTOS, Lucas Maia. 0 materialismo histórico-dialético. Revista Possibilidades, v. 1, n. 2, out./dez. 2004.

SE ELA DANÇA, eu danço - John Lennon, A morte do Cisne - SBT. Disponível em: <https://www.youtube.com/watch?v=RM2Aio9mvNE $>$. Acesso em: jun. 2011.

SILVA, Vanessa Cristina da. Um arte-educador no ensino não formal: um estudo dos sentidos e significados da atividade docente de arte e cultura em medida socioeducativa. 2012. Dissertação (Mestrado em Psicologia da Educação) - Pontifícia Universidade Católica de São Paulo, São Paulo, 2012.

SOARES, Júlio Ribeiro; BARBOSA, Silvia Maria Costa. 0 movimento do sujeito na pesquisa qualitativa de autoconfrontação simples e cruzada. In: ALVES-MAZZOTI, Alda Judith; FUMES, Neisa de Lourdes; AGUIAR,Wanda Maria Junqueira (Orgs.). Estudos sobre a atividade docente: aspectos metodológicos em questão. São Paulo: Educ: Edufal, 2010.

TRIVIÑOS, Augusto Nibaldo. Introdução à pesquisa em ciências sociais: a pesquisa qualitativa em educação. São Paulo: Atlas, 1992.

VAN KOLCK, Odette Lorenção. Testes projetivos gráficos no diagnóstico psicológico. São Paulo: EPU, 1984.

VIGOTSKY, Lev Semenovich. A formação social da mente. São Paulo: Martins Fontes, 2007.

VIGOTSKY, Lev Semenovich. Teoria e método em psicologia. 3. ed. São Paulo: Martins Fontes, 2004.

Recebido em: 30.10 .2013

Aprovado em: 23.09.2014

Vanessa Cristina da Silva é professora na Universidade Anhanguera de Taboão da Serra, mestre em psicologia da educação pela Pontifícia Universidade Católica de São Paulo (PUC-SP).

Claudia Leme Ferreira Davis é professora na Pontifícia Universidade Católica de São Paulo, doutora em psicologia escolar e do desenvolvimento humano, ambos pela Universidade de São Paulo. 
